\title{
The Preparing of the Uni-directional Glass Fiber Metal Laminates and the Fatigue Crack Propagation Characters
}

\author{
Sha $\mathrm{Yu}^{1, \mathrm{a}}$,Bai Shigang ${ }^{2, \mathrm{~b},{ }^{*}, \text { Sha Ning }}{ }^{3, \mathrm{c}}$, Chen Lei ${ }^{1, \mathrm{~d}}$, Guan $\mathrm{Yu}^{1, \mathrm{e}}$ \\ ${ }^{1}$ School of Mechanical Engineering, East University of Heilongjiang,Harbin 150066, China \\ ${ }^{2}$ School of Science, Northeast Agricultural University, Harbin 150030, China \\ ${ }^{3}$ Heilongjiang Province Compute Center , Harbin 150028, China \\ ashayu2004@126.com, bbaishignag1977@126.com, cjinsha0520@sina.com, \\ deichen163@sina.com, emujuguan121@163.com
}

\begin{abstract}
Keywords: Glass fiber reinforced aluminum laminate, Fatigue crack propagation, Crack opening shape
\end{abstract}

Abstract. The 3/2 unidirectional glass fiber metal laminates were developed using LY12-M aluminum alloy and HS2 high strength glass fiber prepreg by the hot pressing and curing progress. The fatigue crack propagation tests of LY12-M aluminum alloy plates and unidirectional glass fiber reinforced aluminum laminates were done. The result showed that the process of the preparing is feasible and the effective bridge stress of glass fiber was obtained. The fatigue crack growth rate of the laminates was $10^{-5} \sim 10^{-4} \mathrm{~mm} /$ cycle, which was an order of magnitude lower than the LY-12 aluminum alloy. The crack opening shape was observed. The crack opening displacement of the glass fiber reinforced aluminum laminates were no obvious change, however, the crack opening displacement of the single layer of LY12-M aluminum alloy increased significantly with the propagation of fatigue crack.

\section{Introduction}

Fiber metal Laminates (FMLs) were firstly developed at Delft University of Technology as a family of hybrid materials that consist of bonded thin mental sheets and fibers embedded in epoxy [1-3].Two variants of FMLs were successively developed: Arall, containing aramid fibers, and Glare, containing glass fibers. The current investigation into fatigue crack propagation behavior focuses on Glare[4-6], which consists of aluminium 2024-T3, S2-glass fibers and the FM94 adhesive system. Glare has become known for its excellent fatigue and has been successively applied to the Airbus A380 as skin materials.

In this paper the LY-12 aluminum alloy sheet and HS2 high strength glass fiber prepreg were used for preparing of the uni-directional glass fiber metal laminates. The $\mathrm{J} 272$ medium temperature adhesive film was inserted between the aluminum alloy layer and glass fiber prepreg layer to enhance the interface strength.

\section{Material and Methods}

\section{Material}

The brand of aluminum alloy, adhesive and reinforced fiber are showed in table 1. The Young's modulus and Yield strength are showed in table 2. 
Table 1 Materials of test

\begin{tabular}{ccc}
\hline Aluminum alloy \& thickness $(\mathrm{mm})$ & Reinforced fiber & Adhesive \\
\hline LY12-M/ $1 \mathrm{~mm}, 3 \mathrm{~mm}$ & HS2 & J-272 \\
\hline
\end{tabular}

Table 2 Material constants

\section{Preparing of the uni-directional glass fiber metal laminates}

The 3/2 uni-directional glass fiber metal laminates were preparing using 3 layer of LY-12 aluminium alloy sheets of $1 \mathrm{~mm}$ thickness , 2 layer of reinforced fiber and 4 layer of adhesive film. Stacking sequence: Al/J272/Glass/J272/A1/J272/Glass/J272/Al.

The temperature of heat curing was $120 \sim 125^{\circ} \mathrm{C}$. The hot pressing time was $2.0 \mathrm{~h}$. The curing pressure was $0.2 \sim 0.4 \mathrm{MPa}$. The phosphoric acid anodizing was used for surface treatment of aluminium alloy sheets.

\section{Specimens}

The specimens are center cracked panels (MT). As shown in Fig.1, the dimensions are $\mathrm{L}=$ $80 \mathrm{~mm}, \mathrm{~W}=40 \mathrm{~mm}$ 。 The crack length is $2 \mathrm{a}$. The specimens had a rectangle cross section of $10 \mathrm{~mm} * 1 \mathrm{~mm}$.

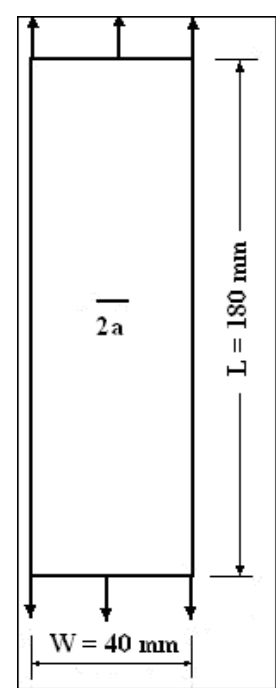

Figure.1 MT specimen geometry

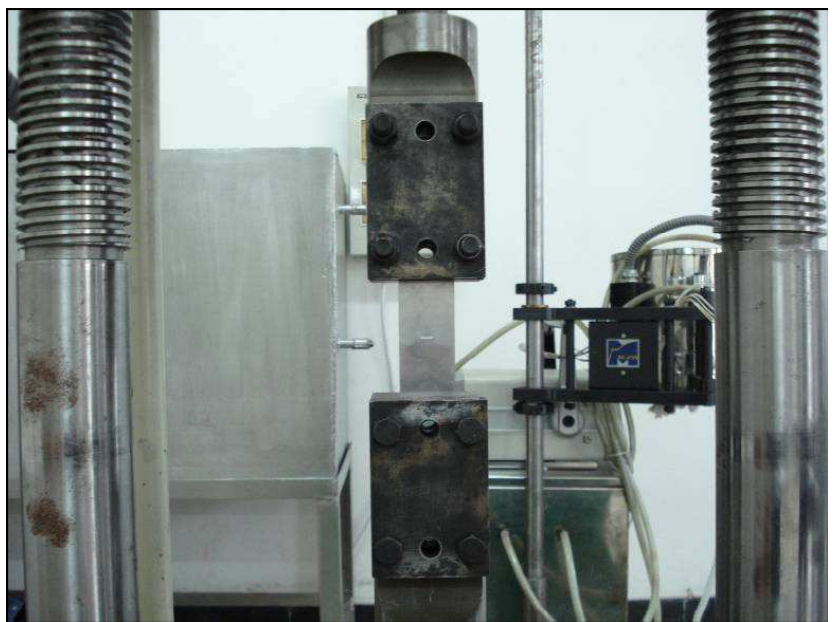

Figure.2 High frequency fatigue testing machine and MT specimen

\section{Test procedures}

Fatigue test was performed on a PLG-100C high-frequency fatigue testing machine under a four baseline $\mathrm{R}$ ratios: $\mathrm{R}=0.1$. Test was conducted in laboratory air, $20^{\circ} \mathrm{C}$. Fig. 2 shows the high frequency fatigue testing machine and MT specimen.

The grips for the MT specimens used in the tests were specially designed such that no bending could take place and the alignment was perfect.

The maximum applied stresses of the applied stress cycle are given in Table 3. The applied maximum tensile loading is $57.6 \mathrm{MPa}$ and the value remained constant. The fatigue damage in these experiments was monitored by taking photos. In this way a permanent record of the deformation and development of fatigue cracks could be recorded. 
Table3 The parameters of the experiment

\begin{tabular}{ccccccc}
\hline Specimens & $\begin{array}{c}\text { Thickness of } \\
\text { specimens }(\mathrm{mm})\end{array}$ & $\begin{array}{c}\text { laminate } \\
\text { structure }\end{array}$ & $\begin{array}{c}\text { fiber } \\
\text { direction }\end{array}$ & $\begin{array}{c}\text { Stress } \\
\text { ratio }\end{array}$ & $\begin{array}{c}\text { maximum tensile } \\
\text { loading } \\
\mathrm{S}_{\max }(\mathrm{Mpa})\end{array}$ & $\begin{array}{c}\text { loading } \\
\text { direction } \\
\theta\left({ }^{\circ}\right)\end{array}$ \\
\hline $\begin{array}{c}\text { Laminates } \\
\text { Aluminum } \\
\text { alloy }\end{array}$ & 3.56 & $3 / 2$ & $0 / 0$ & 0.1 & 57.6 & 0 \\
\hline
\end{tabular}

\section{Test Results}

\section{The fatigue crack growth rate}

The Paris law [5-7]is

$$
\frac{d a}{d N}=C(\Delta K)^{m}
$$

where $C$ and $m$ are constants of material.The half crack length $\left\{\mathrm{a}_{\mathrm{i}}\right\}$, the number of cycles $\left\{\mathrm{N}_{\mathrm{i}}\right\}$ data were used to calculate the fatigue crack growth rate

$$
\left(\frac{d a}{d N}\right)_{j}=\frac{a_{i+1}-a_{i}}{N_{i+1}-N_{i}}, j=i=1,2 \mathrm{~L}
$$

and to calculate the stress intensity factors $\Delta K_{\mathrm{j}}$.

$$
\begin{aligned}
& \left(\frac{d a}{d N}\right)_{j}=\frac{a_{i+1}-a_{i}}{N_{i+1}-N_{i}},=i=1,2 \perp \\
& \Delta K_{j}=\frac{\Delta P}{B} \sqrt{\left(\frac{\pi \alpha_{j}}{2 W}\right) \sec \frac{\pi \alpha_{j}}{2}}
\end{aligned}
$$

where, $\Delta P$ is stress amplitude $\Delta P=P_{\max }-P_{\min }, W$ is the width of specimens,$\alpha_{j}=2 a_{j} / W$.

The a-N curve of fatigue crack propagation of the two MT specimens was draw in the same figure to compare the performance difference of aluminum alloy and the uni-directional glass fiber aluminum alloy laminates. The Fig. 3 give the a-N curve from $2 \mathrm{a}=6.5 \mathrm{~mm}$ to failure. The Fig. 2 indicated that the number of cycles from $2 \mathrm{a}=6.5 \mathrm{~mm}$ to failure of the laminates is more than 10 times aluminum alloy.

The Fig. 4 shows that the fatigue crack growth rate of the LY12-M aluminum alloy is between $10^{-4} \sim 10^{-3} \mathrm{~mm} /$ cycle. Under the same stress intensity factors the fatigue crack growth rate of the uni-directional glass fiber aluminum alloy laminates is between $10^{-5} \sim 10^{-4} \mathrm{~mm} / \mathrm{cycle}$ 。And the difference has increasing trend with the fatigue crack propagation.

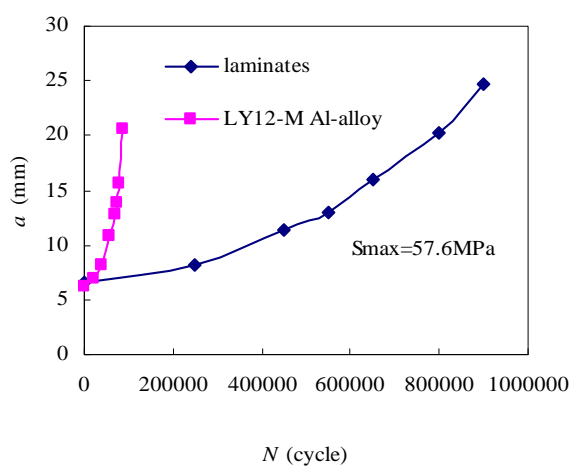

Figure.3 The $a$-N curve of fatigue crack propagation

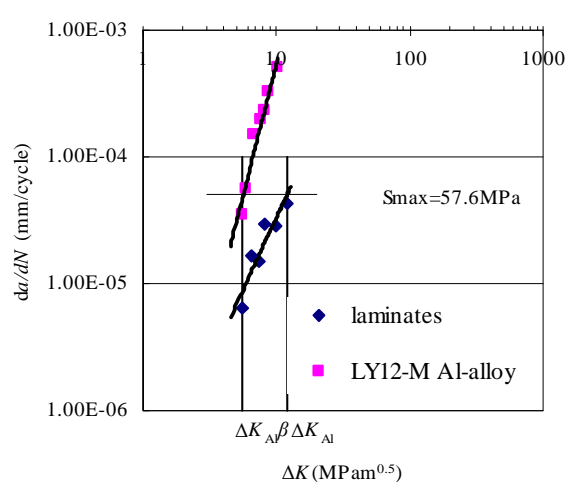

Figure.4 The $d a / d N-\Delta K$ curve of fatigue crack propagation 


\section{The crack opening profile}

With measuring the crack length, the crack opening profile was observed to describe the difference of fatigue property of two specimens.

Fig.5 (a) and (b) show the crack opening profiles for aluminum alloy at the maximum tension load $S_{\max }=57.6 \mathrm{Mpa}$, stress ratio $\mathrm{R}=0.1$. The half crack length increased from $\mathrm{a}=8.0 \mathrm{~mm}$ to $11.0 \mathrm{~mm}$ and the maximum stress intensity factor increased from $\mathrm{Kmax}=10.0 \mathrm{Mpam}^{0.5}$ to $13.0 \mathrm{Mpam}^{0.5}$. Fig.5 (c) and (d) show the crack opening profiles for the uni-directional glass fiber aluminum alloy laminates at the maximum tension load $S_{\max }=57.6 \mathrm{Mpa}$, stress ratio $\mathrm{R}=0.1$. The half crack length increased from $\mathrm{a}=8.0 \mathrm{~mm}$ to $11.0 \mathrm{~mm}$. The maximum stress intensity factor increased from $\mathrm{Kmax}=10.0 \mathrm{Mpam}^{0.5}$ to $13.0 \mathrm{Mpam}^{0.5}$. It is indicated from Fig.6 that the COD (crack opening distance) of uni-directional glass fiber aluminum alloy laminates was far less than the COD of the aluminum alloy sheet. That is corresponding to the difference of the fatigue crack propagation.

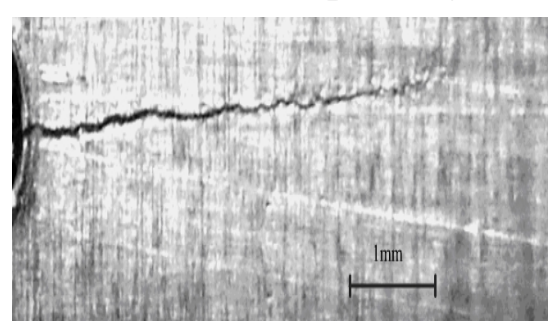

(a)

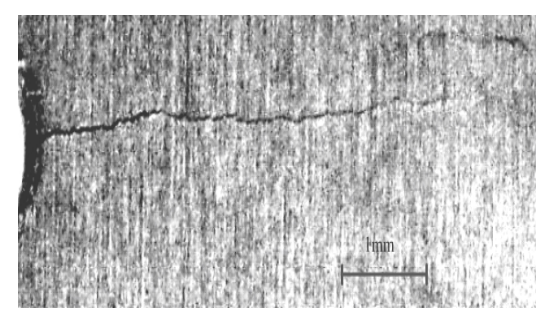

(c)

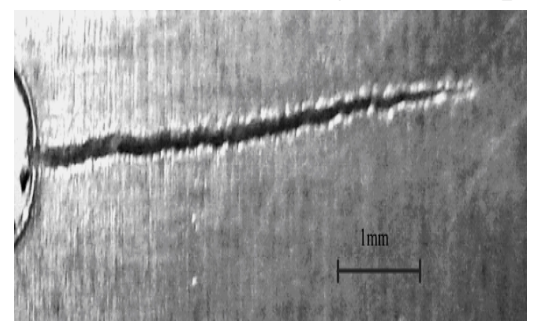

(b)

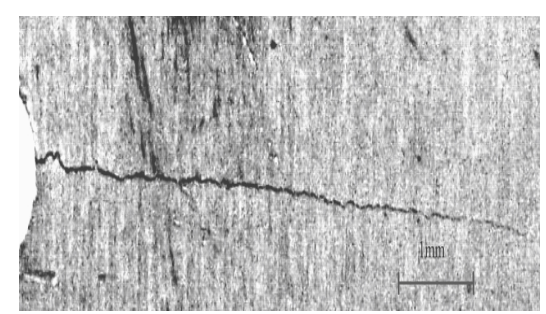

(d)

Figure.5 Crack opening shape of the single plate and laminates

\section{Prediction of fatigue crack growth rate}

Considering the bridging effect of fiber metal laminates in fiber reinforced metal laminates, the effective crack tip stress intensity factor [7-8] is the equation (5).

$$
K_{F M L}=K_{\max }-K_{b r}
$$

$K_{\mathrm{br}}$ is the bridging stress caused by stress intensity factor in equation (5). The fatigue crack growth rate of FML can be obtained by equation (1) and (5).

$$
\begin{aligned}
& \left(\frac{d a}{d N}\right)_{F M L}=C\left(\Delta K_{F L M}\right)^{m}=C(\beta \Delta K)^{m} \\
& \beta=F(a)
\end{aligned}
$$

According to equation (6), equation (8)can be obtained.

$$
\lg \left(\frac{d a}{d N}\right)_{F M L}=\lg C+m \lg \left(\Delta K_{F M L}\right)
$$

With the linear fitting data $\left.\left\{\lg (d a / d N)_{\mathrm{j}}, \lg \Delta K_{\mathrm{j}}\right)\right\}$ of aluminum alloy LY12-M, the fatigue crack growth rate of aluminum alloy LY12-M can be concluded.

$$
\lg \left(\frac{d a}{d N}\right)=-7.4018+4.1366 \lg (\Delta K)
$$




$$
\frac{d a}{d N}=10^{-7.4018}(\Delta K)^{4.1366}
$$

$\mathrm{C}$ and $\mathrm{m}$ are the LY12-M aluminum alloy material constants in equation (6), $\mathrm{C}=10^{-7.4018}, \mathrm{~m}=4.1366$. The correlation coefficient of the fitting equation $\mathrm{R}^{2}, \mathrm{R}^{2}=0.9513$. It can be illustrated that the equation (9) agree well with the available test data. Fig.2 shows $\beta$ can be measured as $\left(\frac{d a}{d N}\right)_{F M L}=\left(\frac{d a}{d N}\right)_{A l}$. Fitting $\beta$ and the half crack length $a$ of equation (6), it can be got the fitting equation (11). The fitting equation $\mathrm{R}^{2}=0.9824$ and the equation (11) agree well with the test data.

$$
\beta=\frac{1.0908}{a^{0.3476}}
$$

The fatigue crack growth rate equation in the fiber direction loading of unidirectional glass fiber reinforced aluminum laminates can be concluded by equation(10) and (6). Fig.6 shows the fitted values of equation (12) agree well with the test data.

$$
\left(\frac{d a}{d N}\right)_{F M L}=10^{-7.4018}\left(\frac{1.0908}{a^{0.3476}} \Delta K\right)^{4.1366}
$$

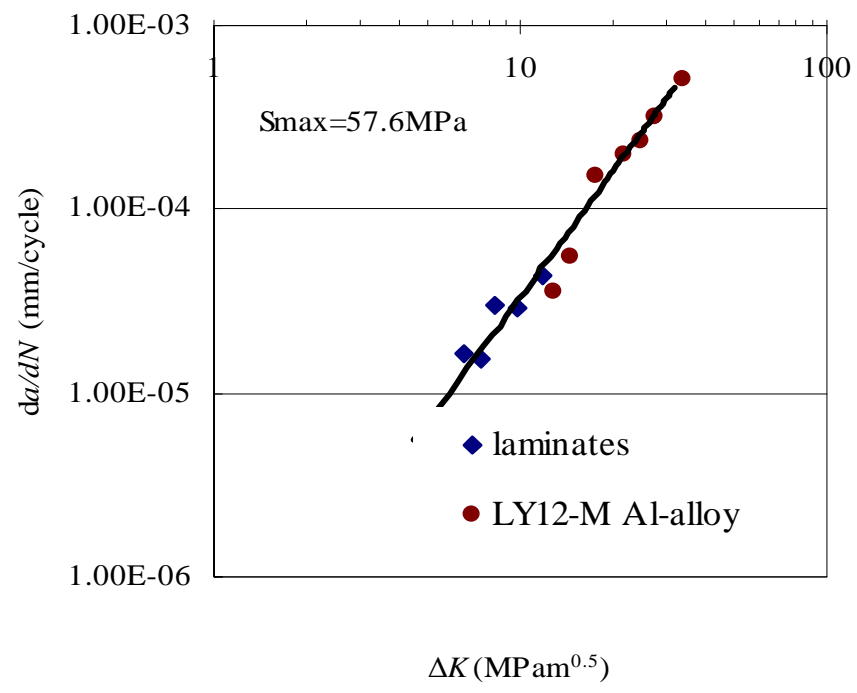

Figure.6 $d a / d N$ fitting line of glass fiber reinforced aluminum laminates

\section{Conclusion}

The 3/2 unidirectional glass fiber metal laminates were developed using LY12-M aluminum alloy and HS2 high strength glass fiber prepreg by the hot pressing and curing progress.In the range of test parameters, the fatigue crack growth rate of the LY12-M aluminum alloy is more than 10 times the one of the uni-directional glass fiber aluminum alloy laminates. The contribution factor $\beta$ was imported to the Paris law to predict the fatigue crack growth rate. The $\beta$ is only the function of the half crack length.With the propagation of fatigue crack, the COD of the aluminum alloy specimens increased obviously. On the contrary, the COD of the aluminum alloy laminates was very small and change slowly. The prepared aluminum alloy specimens acquired the effective bringing and enough interface strength. 


\section{Acknowledgements}

The work was supported by Natural Science Foundation of Heilongjiang Province of China (LC2018025). The authors like to thank East University of Heilongjiang China for the support.

\section{Reference}

[1] Roebroeks and G.H.J.J. [Thesis]. Delft University of Technology. .(1991)

[2] Human, J.J .Fatigue initiation in fibre metal laminates, int.J. Fatigue 28, 366-374. (2006)

[3]Shen Ye,Jian-Guo Gong,Xian-Cheng ect. Acta Metallurgica Sinica,30(09):809-821. (2017), [4]Sun Zhenqi,Huang Minghui.Chinese Journal of Aeronautics,26(03):601-605. (2013)

[5]Lianghua Lin,Zhiyi ect .Journal of Materials Science \& Technology,34(03):534-540. (2018)

[6]X.Li,H.Yuan,J.Y.Sun..Theoretical \& Applied Mechanics Letters,3(04):20-24.(2013)

[7]Y.J.Guo,X.R.Wu, Fatigue \& Fracture of Engineering Materials \& Structures, 21:1133-114.(1998)

[8] Bai Shigang, Sha Yu. International Journal of Fatigue, (110):162-171.(2018) 